\title{
Identificación personal mediante el estudio de los senos frontales. A propósito de un
}

caso.

Personal identification through the study of frontal sinuses. A case report.

\section{J. Lamas ${ }^{1}$, R. Vega ${ }^{1}$ y J. González ${ }^{1}$}

\section{RESUMEN}

La identificación de los cadáveres se realiza, en ocasiones, recurriendo a técnicas radiológicas cuando no existen otros métodos disponibles como ocurre en situaciones de esqueletización, carbonización o restos cadavéricos. Si existen registros radiológicos ante mortem (AM) de la posible víctima, se puede realizar la identificación mediante el estudio comparativo con una radiografía post mortem (PM).

Presentamos el caso de la identificación de un cadáver que apareció en un estado de esqueletización total y con pérdida de muchos huesos, mediante la comparación de las radiografías AM y PM del cráneo, donde eran visibles los senos frontales. Las características morfológicas individuales de estas estructuras permitieron la plena identificación del cadáver.

Palabras clave: senos frontales, radiografía, identificación personal, antropología forense.

Cuad Med Forense 2008; 14(53-54):317-326

\section{ABSTRACT}

Corpse identification is sometimes achieved by $\mathrm{x}$-ray when other possible methods of identification are not applicable, e.g. skeletisation, charred or cadaver remains. If ante mortem (AM) $\mathrm{x}$-ray records are available, it is possible to obtain the identification by the comparison with a post mortem (PM) x-ray.

In this paper we present a personal identification, performed in a cadaver where only the skeleton was preserved and some bones were missing, by comparison of AM and PM $x$-ray analysis of the skull, where the frontal sinuses were visible. The morphological individualistic characteristics of these structures enabled us to identify the cadaver completely.

Key words: Frontal sinuses, $\mathrm{x}$-ray, personal identification, forensic anthropology.

Correspondencia: Josefina Lamas. Complejo Policial de Canillas. Comisaría General de Policía Científica. Servicio Central de Identificación. Sección de Antropología Forense. C/ Julián González Segador, s/n 28043 Madrid.

E-mail: josefina.lamas@dgp.mir.es.

1 Técnicos del Cuerpo Nacional de Policía. Ministerio del Interior. Dirección General de la Policía y la Guardia Civil. Comisaría General de Policía Científica. Sección de Antropología Forense. 


\section{INTRODUCCIÓN:}

La identificación personal ha sido una preocupación constante a través de los tiempos y es el antecedente en el que se basa toda la moderna criminalística.

Desde la identificación facial y visual con el retrato hablado de Bertillón hasta las modernas técnicas basadas en el estudio de marcadores genéticos, existe todo un abanico de posibilidades para la identificación humana en las que el método escogido dependerá de las características que presente el cadáver (putrefacción, esqueletización, carbonización, etc.) y de los medios disponibles de comparación. La lista de posibilidades en métodos de identificación no es, por tanto, cerrada ni excluyente.

Se busca, ante todo, que las técnicas empleadas lleven a cabo una identificación positiva. La identificación positiva es el resultado de la información que es exclusiva de un solo individuo, con elementos tales como el DNA, huellas dactilares, prótesis con su número de serie, anomalías esqueléticas contrastables y la identificación radiográfica.

La necroidentificación o identificación cadavérica será el resultado de un estudio realizado por especialistas forenses, antropólogos, dactiloscopistas, etc., quienes, con sus conocimientos, pueden llegar a establecer el dictamen de identidad [I]. Básicamente, consiste en la comparación o cotejo de unos datos obtenidos en el estudio pormenorizado y minucioso de un cadáver (datos post-mortem -PM-) con aquellos otros facilitados por familiares (datos ante-mortem, -AM-). Entre estos estudios destacamos la comparación de radiografías de cráneo en las que se estudian los senos frontales.

El cráneo es una parte del esqueleto que aporta mucha información en el proceso de identificación de un cadáver esqueletizado [2]. Proporciona datos fisonómicos y además tiene un elevado potencial de identificación positiva mediante estudio radiográfico comparativo. Es muy frecuente en nuestro medio que la población tenga en su domicilio o en un centro sanitario, radiografías AM que se realizaron en su día para estudio de traumatismos craneales, sinusitis, etc. Por tanto, puede permitir la comparación de las radiografías AM con las PM, principalmente mediante el estudio de los senos frontales. Los senos frontales, nasales y paranasales son un conjunto de cavidades aéreas que se encuentran en los huesos frontales, esfenoides, etmoides y maxilar superior y que comunican con las fosas nasales (Fig. IA) [3]. No están presentes en el nacimiento, empezando su desarrollo al final del primer año de vida. Los senos frontales se dividen de forma completa o incompleta mediante el septum en una parte derecha y una izquierda. Los lados derecho e izquierdo se

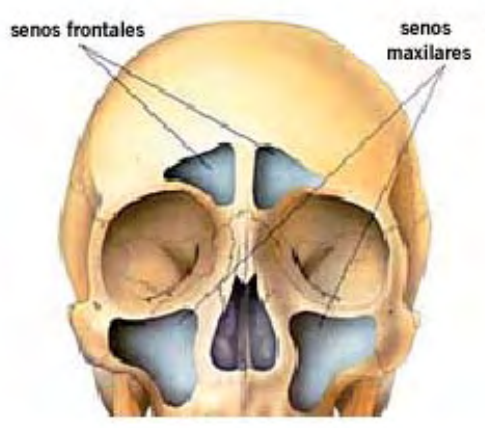

Figura 1A. Anatomía de los senos frontales. Figura 1B. Agenesia de senos frontales.

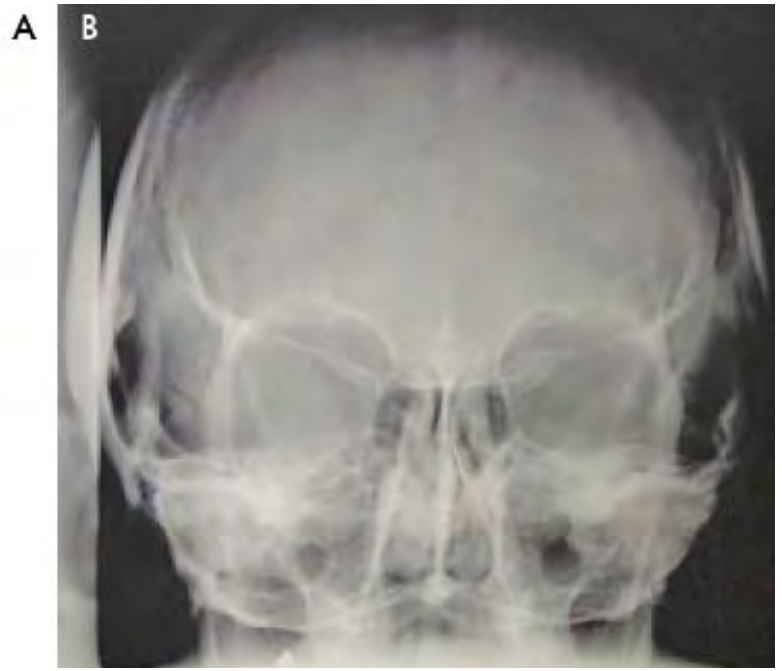


denominan celdas. Son variables en forma, tamaño y simetría. Normalmente, están más desarrollados en el hombre que en la mujer. La variabilidad se aprecia en la configuración del borde superior de estas celdas, siendo este festoneado su principal característica individual. La parte inferior de las mitades de los senos o celdas pueden exhibir otras celdas que corresponden a los senos etmoidales. Las medidas medias son: 20-23 mm de altura, 25-27 mm de anchura y $10-15$ mm de profundidad. Pueden existir agenesias de los senos, que oscilan alrededor del 5 \% [4] (Fig. IB). En ausencia de senos, la radiografía mostrará una falta de neumatización que imposibilitara la identificación del sujeto, aunque permita descartar posibles candidatos $[5,6]$, Múltiples estudios han permitido establecer que el contorno de los senos frontales es especifico de cada individuo y se mantiene constante a través de la vida del sujeto [7].

\section{LA IDENTIFICACIÓN RADIOLÓGICA:}

La técnica de la Antropometría Radiográfica fue creada por Levinson en 1899. En 1921, Schuller planteó la posible utilización de la radiografía de los senos frontales como un elemento identificativo. Distintos autores como Cubert y Law (1927), Myers (1928), Luís Delclós (1934), Turpin y Tisserand (1942), Schuller (1943), Thorme y Thyberg (1953), Neiss (1962), Asherson (1965), Zubizarreta (1966) Mann y Fetteh (1968) utilizaron como método de identificación la individualidad de los senos frontales [8].

En la actualidad el estudio radiológico de los senos frontales permite realizar una identificación positiva, ya que no hay dos individuos que tengan senos frontales idénticos [9].

Merece destacar en este campo la aportación de Wilton Krogman (1962). Aportó las tres bases de observación y tres de medición para establecer las concordancias entre las radiologías AM y PM. La primera observación consiste en examinar la línea del septum para observar si se inclina hacia la derecha o hacia la izquierda y en los casos de septum parcial se observa su forma y longitud. La segunda observación se refiere al festoneado del borde superior del seno y el número y forma de las celdas. La tercera observación se centra en la zona inferior para apreciar si hay fusiones con el seno etmoidal. Además de estas observaciones no métricas, Krogman propone la construcción de una parrilla sobre las radiografías practicadas. La parrilla se construye trazando en primer lugar una línea a lo largo del plano del septum. Luego se dibuja una línea adyacente al borde superior de los senos, seguido de una línea perpendicular adyacente a la parte más externa de las mitades derecha e izquierda. Finalmente se dibuja una línea paralela a la zona más superior central al yugo esfenoidal. En este punto se toman tres medidas: la altura de la línea media, la anchura del seno frontal y la anchura del seno frontal izquierdo [ 10$]$.

Cuando hay concordancia entre las radiografías AM y PM tanto en lo referente a la morfología y las medidas, la identificación puede considerarse finalizada y positiva.

En aquellos casos en que la posición y la distancia de ambas radiografías no coincidan, se dificulta enormemente la comparación por simple inspección visual [ I I], por lo que, para una adecuada identificación se requiere que las radiografías PM se practiquen siguiendo las mismas técnicas que las AM. Esto requiere que la distancia del tubo de $R \times$ al cráneo y el espacio entre el sujeto y la placa tengan la misma distancia que en la radiografía AM, ya que de otra forma, la divergencia del haz puede causar una magnificación de los senos e impedirá que los ángulos sean comparables y concordantes. Los efectos de estos problemas pueden resolverse realizando tantas radiografías PM como sea necesario. Otro problema a tener en cuenta es la claridad de la radiografía AM, ya que a veces aporta unos contornos borrosos, poco marcados e imprecisos que dificultan la comparación. 
Este problema de comparaciones radiográficas se le planteó al Equipo Argentino de Antropología Forense [12] y para solucionarlo diseñaron un método utilizando técnicas de procesamiento digital de imágenes correspondientes a las etapas de segmentación y representación de formas $[13, \mid 4]$. Con el objeto de obtener el contorno de los senos frontales se utilizó la técnica del gradiente morfológico que combina las operaciones básicas de la morfología matemática: erosión y dilatación $[15,16]$.

Las representaciones de contorno incluyen descriptores globales de forma tales como redondez, factor de forma, elongación, convexidad o código cadena. Aunque proveen una buena representación del objeto en estudio, usualmente se combinan con otras técnicas para mejorar su rendimiento como los descriptores de Fourier (DFs) que son métodos de reconocimiento bidimensional a través de las siluetas que caracterizan mejor el contorno de un objeto ya que sólo objetos con siluetas similares tienen descriptores similares [17].

En los últimos 25 años, han sido varios los autores que se han dedicado a estudiar los senos frontales como estructura que permite la identificación personal $[18,19]$.

\section{PRESENTACIÓN DEL CASO:}

Se trata de unos restos óseos en los que el estudio comparativo de las radiografías (indubitadas) de senos frontales AM con las dubitadas realizadas PM, pudo establecer su plena identidad.

\section{a) Antecedentes.}

La Brigada Provincial de Policía Científica de A Coruña, remitió a la Sección de Antropología del Servicio Central de Identificación de esta Comisaría General de Policía Científica unos restos óseos que habían sido localizados en los bajos de un edificio en esta ciudad. Se solicitaba el estudio antropológico para establecer su identificación.

Inventario del material recibido:

- Cráneo con mandíbula.

- Tibia y peroné izquierdos

- Fémur derecho

- Húmero, cúbito y radio derechos

- Pelvis y sacro

- Siete vértebras cervicales y las tres primeras dorsales

\section{b) Metodología.}

Antes de efectuar ninguna manipulación, se realizaron fotografías de los elementos óseos en el mismo estado en que fueron recibidos. Para poder apreciar todas las características de los huesos objeto de estudio se procedió a la limpieza de los mismos, sumergiendo el cráneo y las dos primeras vértebras cervicales en hipoclorito sódico al 50 \% durante 24 horas y cepillando los demás huesos cuidadosamente, a fin de eliminar los restos que conservaban. Posteriormente, se realizaron estudio macroscópico y antropométrico y radiológico.

\section{c) Examen macroscópico.}

Todos los elementos óseos se colocaron en posición anatómica. Las características macroscópicas eran propias de la especie humana. 
Los restos, tras su limpieza, fueron fotografiados individualmente, realizándose en alguno de ellos fotografías de detalle de algún elemento considerado de interés.

\section{I) CRÁNEO:}

\section{c. I. I Esplacnocráneo.}

Se apreció la morfología del macizo facial y de las suturas. (Fig. 2A). Próximo a la unión fronto-nasal se conservaban todavía restos de la sutura metópica, que sobrepasaba el punto glabela.

Los huesos nasales presentaban desviación hacia el lado derecho mostrando además la zona de unión al frontal profunda y estrecha. El foramen piriforme presentaba el lado derecho más estrecho y largo que el izquierdo.

\section{c.l.2 Neurocráneo.}

En la bóveda craneal se observaba la sutura coronal y sagital con los bordes próximos y múltiples puntos de osificación, especialmente en la parte lateral de la sutura coronal y en la posterior de la sutura sagital (Fig. 2B ).

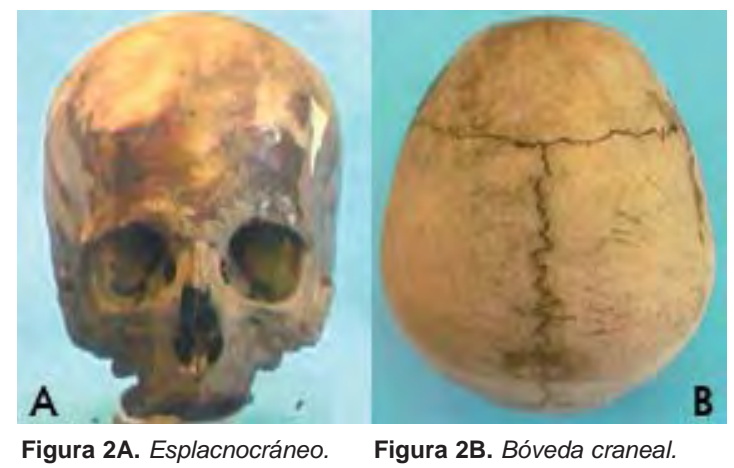

En norma lateral derecha se conservaban todas las suturas, con la escama del temporal adherida a la del parietal. La apófisis mastoides era robusta y larga.

En norma lateral izquierda, se apreciaba en la unión temporo-parietal el dibujo de todas las suturas. La escama del temporal estaba adherida al parietal. La apófisis mastoides presentaba una morfología similar a la del lado derecho.

En norma posterior, se observaba la sutura lambdoidea aunque con múltiples puntos donde los bordes se habían fusionado.

En norma inferior se apreciaban todas las estructuras con una morfología normal, presentando las dos ranuras digástricas profundas y muy marcadas (Fig. 3A). En la protuberancia occipital se observaba una excrecencia ósea importante, característica anatómica frecuente en los varones, así como la cresta occipital y las líneas nucales muy señaladas.

En el paladar óseo, la sutura incisiva había desaparecido. La sutura palatina longitudinal presentaba los bordes rugosos, con múltiples puentes óseos. La sutura palatina transversa tenía los bordes unidos en casi todo su recorrido, presentando asimismo bastantes rugosidades y exostosis. Se apreciaba ausencia de todas las piezas dentarias con reabsorción ósea indicativos de pérdida no reciente (Fig. 3B). 


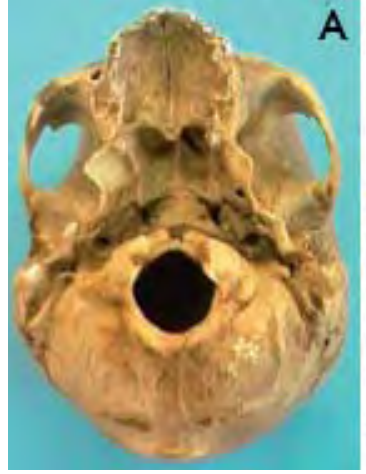

Figura 3A. Base de cráneo.

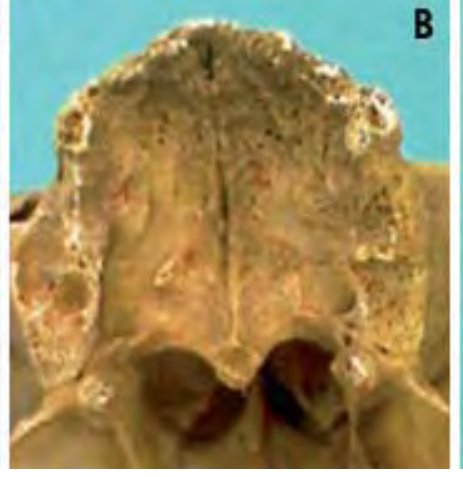

Figura 3B. Paladar óseo.

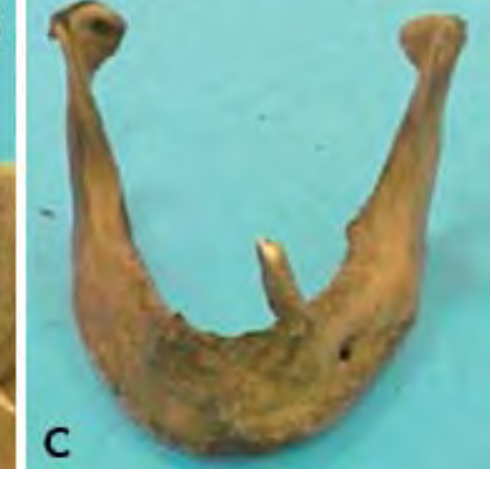

Figura 3C. Mandíbula.

\section{Cl.2 Maxilar Inferior.}

El maxilar presentaba el mentón con una morfología ovalada y los ángulos goníacos muy marcados. En el borde inferior del mentón, el hueso aparece con rugosidades, posiblemente como reacción antigua frente a algún tipo de traumatismo. Solo estaba presente una pieza dentaria que correspondía al incisivo lateral inferior izquierdo (pieza $n^{\circ} 32$ ). El resto de las piezas dentarias estaban ausentes y con reabsorción mandibular, lo que indica pérdida no reciente (Fig. 3C).

\section{c.2) TRONCO:}

\section{c.2. I Columna vertebral:}

Se estudiaron las siete vértebras cervicales y tres dorsales remitidas. Las vértebras cervicales presentaban, especialmente el atlas y el axis, signos de artrosis.

\section{c.2.2 Pelvis:}

Los huesos que conforman la cintura pélvica, sacro y ambos coxales, se encontraban separados. Se reconstruyó la cintura pelviana, uniéndola, para observar claramente su morfología (Fig. 4A).

En el sacro se apreciaban las vértebras fusionadas, quedando un leve vestigio de la zona intervertebral.

El coxal derecho presentaba una morfología normal, apreciándose signos de artrosis en el límite anterior del agujero obturador.

En el coxal izquierdo se apreciaban algunas alteraciones: En los bordes de la superficie auricular había múltiples excrecencias óseas, que en algunos puntos superaban los $20 \mathrm{~mm}$ de altura y que, en el borde inferior de la superficie auricular, se continuaban hacia la parte posterior del ilion (Fig. 4B y 4C).

A nivel de la rama isquio-pubiana se observaba una masa ósea desestructurada, con múltiples espículas. Esta proliferación exagerada de hueso sería la respuesta del organismo ante una fractura localizada en esta zona, dando como resultado un callo de fractura muy tosco (Fig. 4D).

El foramen obturador estaba parcialmente ocupado por múltiples exóstosis que partían del callo antes descrito, y que son evidentes tanto en la cara interna como externa (Fig. 4D).

La sínfisis del pubis y la fosa acetabular no presentaban alteraciones importantes. 

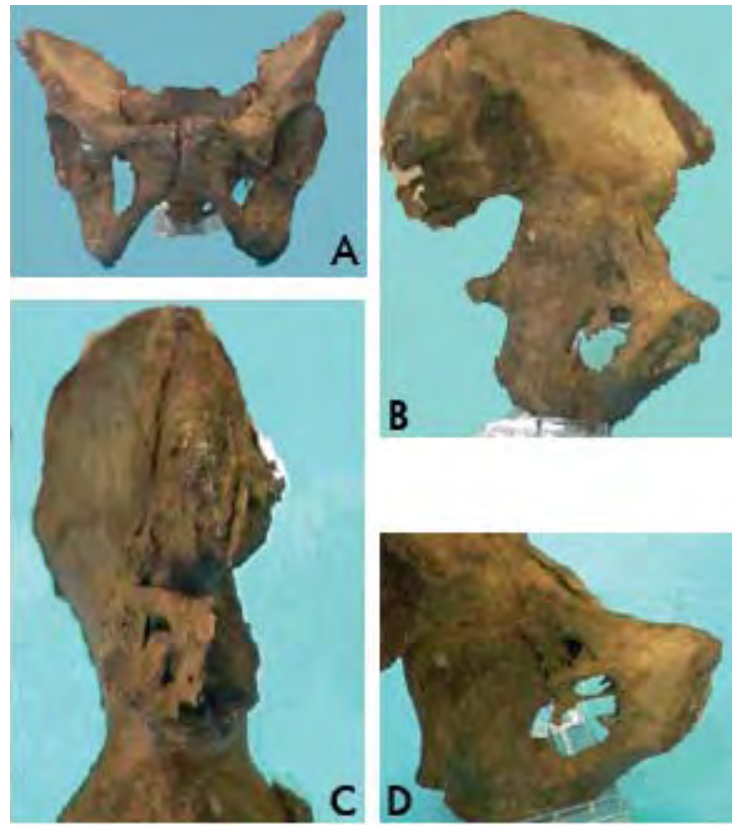

Figura 4A. Pelvis. Figura 4B. Excrecencias óseas.

Figura 4C. Excrecencias óseas. Figura 4D. Callo de fractura.

\section{C.3) EXTREMIDADES SUPERIORES.}

Solo pudieron estudiarse los huesos correspondientes al antebrazo y brazo derechos (Fig. 5A), que ofrecían las siguientes particularidades:

El húmero presentaba pérdida de tejido óseo, dejando al descubierto la sustancia esponjosa en la zona medial de la cabeza y cuello anatómico, cara posterior de la tróclea y cara externa del cóndilo (Fig. 5B). El cúbito en el lado radial o externo de la epífisis proximal, presentaba parte del olécranon con perdida de tejido óseo, dejando al descubierto sustancia esponjosa. En la parte posterior de la epífisis distal casi la totalidad de la apófisis estiloides había desaparecido, dejando al descubierto el canal medular. El radio presentaba perdida de sustancia ósea en ambas epífisis dejando al descubierto el tejido esponjoso en la extremidad proximal en la cara anterior del cuello del radio, y en la distal parte de la apófisis estiloides. La morfología de estas pérdidas de tejido óseo eran compatibles con la acción depredadora de pequeños roedores, tipo ratón o rata.
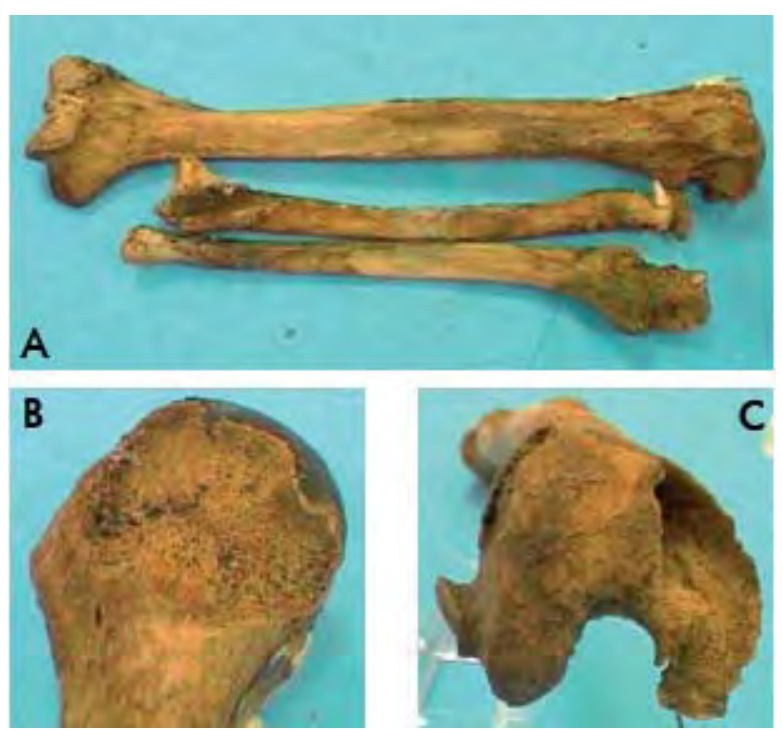

Figura 5A. Huesos de brazo y antebrazo derecho. Figura 5B. Acción de los roedores. Figura $5 \mathrm{C}$. Acción de los roedores en fémur. 


\section{C.4) EXTREMIDADES INFERIORES.}

Solo pudieron estudiarse en la extremidad inferior derecha el fémur y en la izquierda la tibia y peroné.

El fémur derecho, en su extremidad proximal, cara dorsal, presentaba perdida de tejido óseo dejando al descubierto sustancia esponjosa en el trocánter mayor y parte de la cabeza femoral. En la epífisis distal presentaba perdida de la casi totalidad de los dos cóndilos. El cóndilo externo tenía un color grisáceo con restos de tierra, probablemente por haber estado esta zona en contacto con el suelo. Esta pérdida de tejido óseo, al igual que los huesos descritos anteriormente, era compatible con la acción depredadora de roedores (Fig. 5C).

La tibia izquierda presentaba pérdida de la mayor parte de la epífisis proximal dejando al descubierto la sustancia esponjosa, pudiéndose ver la cavidad medular. Esta pérdida de tejido óseo podría atribuirse a la acción depredadora de roedores. En su cara lateral interna presentaba restos de tierra, posiblemente por haber estado esta parte en contacto con el suelo. En el tercio medio de la diáfisis se apreciaba una proliferación de tejido óseo, que daba lugar a un callo de fractura. Esta lesión antigua seguía una trayectoria diagonal descendente, con recorrido anteroposterior.

El peroné presentaba pérdida de parte de la epífisis proximal dejando al descubierto substancia esponjosa y la cavidad medular. La pérdida podría atribuirse de la acción depredadora de roedores. En el tercio medio de la diáfisis, y coincidiendo con la lesión descrita en la tibia, se observaba una importante proliferación ósea, con crecimiento predominante hacia la zona medial del hueso. Esta alteración indicaba la reacción del organismo para restaurar una fractura diafisaria. Sin embargo, al observar el peroné en su cara anterior se apreciaba una desviación de ambos extremos de la zona fracturada, quedando la parte distal de la misma superpuesta y en un plano anterior al extremo proximal, lo que indicaría una ausencia de tratamiento reductor y alineación del hueso tras su fractura.

\section{d) Deducciones antropológicas.}

\section{I) DeterMinACIÓN DEL SEXO.}

En el cráneo se observaban los arcos superciliares muy prominentes y borde orbital romo, en la parte anterior. En la zona posterior se apreciaban la protuberancia occipital, la cresta occipital y las líneas occipitales superior e inferior con mucho relieve (Fig. 2A).

En la base del cráneo, las apófisis mastoides eran grandes, con las ranuras digástricas muy marcadas.

En la pelvis, se apreciaba que la forma del orificio central, limitado en la cara anterior por el sacro, en la cara posterior por la sínfisis, y a ambos lados por la línea innominada, era triangular, con el diámetro medio o antero-posterior mayor que el transverso.

El arco subpúbico era pequeño, ligeramente convexo y alto. La escotadura ciática mayor es estrecha y baja y el foramen obturador tenía forma redondeada.

Las características anatómicas obtenidas del cráneo y pelvis, permiten determinar que pertenecía a un varón.

\section{D.2) DeterminACIÓN DE LA EDAD.}

El estudio para determinar la edad aparente se realizó sobre la situación de la sínfisis del pubis, el cierre de las suturas palatinas y las suturas del cráneo.

La sínfisis del pubis presentaba ligera depresión de la superficie, con un moderado reborde en la parte dorsal, observándose crecimiento externo ligamentoso en borde ventral. Para el cálculo 
de la edad por el estado de la sínfisis del pubis, se utilizó el método de Suchey y Brooks (1999) [20]. Estos datos permitían ubicarlo en el nivel $\mathrm{V}$, estableciendo la edad en un periodo comprendido entre los 27 y 66 años.

En el paladar óseo, la sutura incisiva había desaparecido. La sutura palatina longitudinal presentaba los bordes rugosos, con múltiples puentes óseos. La sutura palatina transversa tenía los bordes unidos, especialmente en el lado derecho (Fig. 3B).

En la bóveda craneal se observaban las suturas coronal, sagital y lambdoidea con los bordes separados y múltiples puntos de osificación (Fig. 2B).

La determinación de la edad aplicando la formula de Masset (basada en grado de cierre de las suturas exocraneales) [2I] con resultado relativo a la edad de 67,65 +/- |4,78 (53-8I años).

\section{D.3) DETERMINACIÓN DE LA ESTATURA.}

Se tomó como referencia el fémur derecho, cuya longitud era de $410 \mathrm{~mm}$. La estatura correspondiente, según las tablas de Mendonça (2000) [22] sería aproximadamente de I57 \pm 6,90 $(|5|-164 \mathrm{~cm})$.

Con los datos obtenidos se pudo establecer:

- Se trataba de un esqueleto incompleto

- Correspondía a un varón, de edad aproximada a $67 \pm 14$ años (53-8I años) y una estatura aproximada de I,57 m.

- Como datos fisonómicos destacaba que el cráneo, en norma superior, era proporcionado, en norma posterior tenía desarrollo vertical y en norma lateral era alto. El aspecto de la cara era proporcionado entre anchura y longitud y la nariz era alargada.

- Las lesiones en la extremidad inferior izquierda eran antiguas y se localizaban en la rama isquio-pubiana del coxal, en la diáfisis de la tibia y en la diáfisis y cuello del peroné. Los callos de fractura del coxal y del cuello del peroné mostraban un proceso regenerativo óseo más anárquico e intenso que en las fracturas diafisarias apreciadas.

- Existían lesiones en extremidades superiores e inferiores post-mortem, producidas muy probablemente por roedores.

\section{e) Pruebas complementarias.}

Mediante la investigación policial se orientó la posibilidad de que los restos óseos analizados correspondieran a un varón concreto desaparecido. Por este motivo se solicitó al Juzgado de Instrucción correspondiente los datos clínicos y radiológicos que pudieran existir en los hospitales de esta ciudad.

El Juzgado remitió una serie radiográfica aportada por el Hospital de referencia entre la que se encontraba una imagen del cráneo, de proyección postero-anterior, en la que eran visibles los senos frontales (Fig. 6A). Se realizó una radiografía del cráneo, en la misma posición que la indubitada (Fig. 6B). Se utilizó un aparato generador de Rx portátil, modelo XR200, con una intensidad de 5 pulsos y a una distancia

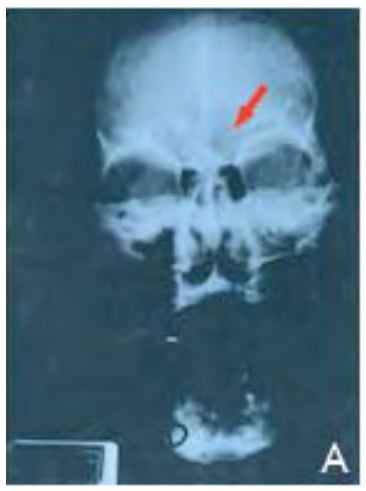

Figura 6A. Rx de cráneo AM con los senos frontales. Figura 6B. Rx post-mortem de cráneo.

senos frontales.

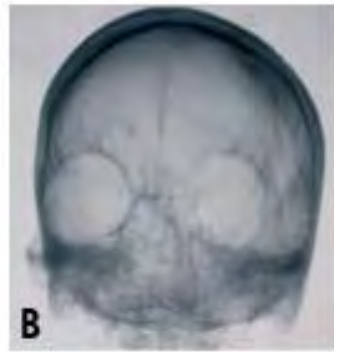


aproximada de $50 \mathrm{~cm}$. La imagen se reveló, imprimiéndose directamente en papel fotográfico marca Polaroid 803

Las imágenes de ambas radiografías se capturaron con un escáner marca Epson GT 5500 y posteriormente, con el programa informático Adobe Photoshop 5.I, se ampliaron las zonas correspondientes a los senos, con el fin de facilitar el estudio de los mismos.

El examen de las dos radiografías, AM y PM mostraban una total analogía morfológica de los senos frontales. Fue especialmente significativa e individualizadora, la imagen densa circular localizada en la zona ápico-lateral del seno frontal derecho (Fig. 7A y 7B).

La total analogía morfológica de los senos frontales de la radiografía AM y PM permitieron establecer que el cadáver encontrado correspondía a la persona que se intentaba identificar.

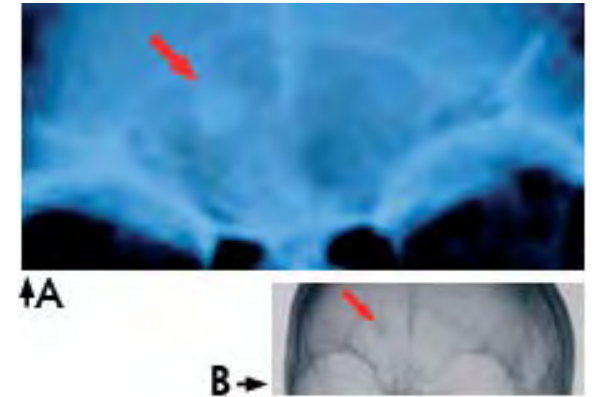

Figura 7A. Detalle de los senos en la rx antemortem. Figura 7B. Detalle de los senos en la rx post-mortem.

\section{CONCLUSIONES:}

El caso presentado muestra la plena vigencia y eficiencia diagnóstica de la identificación positiva de un esqueleto incompleto mediante técnicas de superposición radiográfica de senos.

\section{BIBLIOGRAFÍA:}

I. Abejón P. Antropología Forense: la ciencia que hace hablar los huesos. México 2008

2. Iscan, MYr. Craniofacial Image Analysis and Reconstruction. Forensic Analysis of the Skull: Craniofacial Analysis, Reconstruction, and Identification. Ed. Mehmet Iscan and Richard Helmer. New York: Wiley-Liss, Inc. 1993.

3. Sutton. D. Tratado de radiología e imágenes diagnósticas. Tomo II Salvat Editores, Barcelona. 1985.

4. Byers SN. Introduction to Forensic Anthropology. A Textbook. Second Edition. Pearson Education, Inc. Boston, 2005.

5. Velán 0. Diagnóstico por imágenes de la cara, cráneo y endocráneo. Radiografías simples, tomografía convencional. Angiografía. Tomografía computarizada. Editorial JIMS, Barcelona. 1985.

6. Earwaker J. Anatomic variants in sinonasal CT. Radiographics 1993;13:381-415.

7. Marlin DC, Clark MA, Standish SM, Identification of human remains by comparison of frontal sinus radiographs: a series of four cases. J Forensic Sci 1991;36:1765-1772.

8. Merabishvili G, Superposición de imágenes. Identificación facial bidimensional. Tesis Doctoral. Universidad de Barcelona 2006 .http://www.tesisenxarxa.net/TDX-1003107-I2202I/

9. Christensen J. Testing the reliability of frontal sinuses in positive identification. J Forensic Sci. 2005;50:18-22.

10. Krogman WM. The Human Skeleton in Forensic Medicine, first ed.: Charles C Thomas, Springfield, IL 1962.

II. Reichs KJ. Forensic Osteology: Advances in the Identification of Human Remains, Charles C. Thomas., Springfield, IL 1986.

12. Cohen Salama M. Tumbas anónimas. Informe sobre la identifica- ción de restos de víctimas de la represión ilegal. Catálogos. Buenos Aires. 1992

13. Gonzalez R, Woods R. Digital Image Processing, Prentice Hall, Upper Saddle River, N], USA, 2nd edition, 2002.

14. Russ JC. The Image Processing Handbook, 2nd edition. CRC Press, Boca Raton, FL, USA, 1995.

15. Serra J. Image Analysis and Mathematical Morphology, vol I, London, Academic Press, 1982.

16. Pastore J, Moler, E. Identificación de senos frontales mediante factores de forma y descriptores de Fourier. IEEE Latin America Transactions 2004;2(3):157-161.

17. Ubelaker DH. Positive identification from the radiographic comparison of frontal sinus patterns. In TA Rathbun and JE Buikstra (eds), Human Identification, Charles C Thomas, Springfield, IL, 1984, pp. 399-4II.

18. Quatrehomme G, Fronty P, Sapanet M, et al. Identification by frontal sinus pattern in Forensic Anthropology. Forensic Sci Int 1996;83:147-153.

19. Ferreira da Silva R, Bevilacqua F, Cavalcanti I, et al. The forensic importance of frontal sinus radiographs. J Forensic Leg Med 2009;16:18-23.

20. Brooks S, Suchey JM. Skeletal age determination based on the os pubis: A comparation of the Acsádi-Nemeskéri and and SucheyBrooks methods. Human Evolution 1999;5 (3):227-238.

21. Masset $C$. Estimation de l'age au décés par les sutures craniennes. These Universite Paris VII, 1982.

22. Mendonça MC. Estimation of height from the length of long bones in a portuguese adult population. Am J Phys Anthropol 2000;112:39-48. 